\title{
EL DEBATE JURIDICO-POLITICO DEL PARLAMENTO ALEMAN DEL 10 DE MARZO DE 1965 COMO ANTECEDENTE INMEDIATO DE LA CONVENCION DE LAS NN.UU. SOBRE LA IMPRESCRIPTIBILIDAD DE LOS CRIMENES DE GUERRA Y DE LOS CRIMENES DE LESA HUMANIDAD
}

\author{
THE JURIDICAL-POLITICAL DEBATE OF THE GERMAN PARLIAMENT OF \\ MARCH 10, 1965, AS AN INMEDIATE BACKGROUND TO THE UN \\ CONVENTION ON THE NON-APLICABILITY OF STATUTORY LIMITATIONS \\ TO WAR CRIMES AND CRIMES AGAINST HUMANITIY
}

Humberto Umeres Alvarez*

\section{RESUMEN}

El presente artículo se contrae a reseñar y comentar el debate histórico que tuvo lugar en el Parlamento alemán, el 10 de marzo de 1965, sobre la imprescriptibilidad de los crímenes nazis, como antecedente inmediato de la Convención de las Naciones Unidas sobre la Imprescriptibilidad de los Crímenes de Guerra y de los Crímenes de Lesa Humanidad, de 1968.

Palabras clave: Estado, política, Estado de Derecho, principios como nulla poena sine lege y ne bis in idem, irretroactividad de la ley penal, imprescriptibilidad, prescripción, seguridad jurídica, derecho formal y material, justicia, genocidio.

\section{ABSTRACT}

This writing have the purpose to reviewing and commenting on the historical debate that took place in the German Parliament, on March 10, 1965, on the Non-Applicability of Statutory Limitations to nazi crimes, as an immediate antecedent to the United Nations

\footnotetext{
* Es diplomático de carrera, egresado con el Primer Puesto de la Academia Diplomática. Es abogado y licenciado en relaciones internacionales. Ha cursado estudios regulares de Ciencia Política en la especialidad de Relaciones Internacionales en la Facultad de Ciencias Políticas Otto Suhr de la Universidad Libre de Berlín (1970-1971) y en la Facultad de Filosofía y Ciencias Políticas de la Universidad Renana Friedrich Wilhelm de Bonn (1974-1977). Recibió un Doctorado Honoris Causa de la Universidad de Kursk de la Federación de Rusia. Ha sido profesor en la Academia Diplomática del Perú de Teoría de las Relaciones Internacionales, Política Exterior del Perú y Ciencia Política, así como de Derecho Internacional Público en la Pontificia Universidad Católica del Perú. Ha sido dos veces Embajador Extraordinario y Plenipotenciario del Perú en la Federación de Rusia. Ha sido condecorado con la "Orden al Mérito por Servicios Distinguidos, en el grado de Gran Cruz", del Perú, y con la "Orden la Cruz al Mérito, Primera Clase”, de la República Federal de Alemania.
}

Con el presente artículo, el autor formaliza su incorporación como Miembro Asociado, conforme a lo dispuesto por el Consejo Directivo de la Sociedad Peruana de Derecho Internacional, mediante Acta del 13 de diciembre de 2018. 
Convention on the Non-Applicability of Statutory Limitations to War Crimes and Crimes Against Humanity, of 1968.

Keywords: State, politics, rule of law, principles such as nulla poena sine lege and ne bis in idem, non-applicability of statutory limitations, statute of limitations, legal certainty, formal and material law, justice, genocide.

\section{INTRODUCCIÓN}

La Convención las Naciones Unidas sobre la Imprescriptibilidad de los Crímenes de Guerra y de los Crímenes de Lesa Humanidad fue aprobada por Resolución No 2391 de la XXIII Asamblea General de la Organización, el 26 de noviembre de 1968, y entró en vigor el 11 de noviembre de 1970.

El artículo I de la Convención señala que "Los crímenes siguientes son imprescriptibles cualquiera que sea la fecha en que se hayan cometido ${ }^{l}$ : a) Los crímenes de guerra según la definición dada en el Estatuto del Tribunal Militar Internacional de Nüremberg, de 8 de agosto de 1945, y confirmada por las Resoluciones de la Asamblea General de las Naciones Unidas 3(I)... y 95 (I) ... de 1946..."; y, b) "Los crímenes de lesa humanidad cometidos tanto en tiempo de guerra como en tiempo de paz," también según la definición del Tribunal de Nüremberg, confirmadas por las mismas Resoluciones de las NN.UU.

De acuerdo a su contenido ad litteram y a su espíritu, la Convención es uno de los documentos más importantes en la historia del proceso de codificación del derecho penal internacional en la medida en que tipifica como delitos los crímenes de guerra y de lesa humanidad recurriendo a las definiciones correspondientes del Estatuto del Tribunal Militar Internacional de Nüremberg y, creando justicia, establece jurídicamente la imprescriptibilidad de esos crímenes, todo lo cual se constituye en derecho internacional obligatorio para todas las Partes del Sistema de las NN.UU. que la han firmado, ratificado o adherido a ella. Como crímenes de guerra la Convención también incluye a las infracciones graves enumeradas en los Convenios de Ginebra, de 12 de agosto de 1949, para la protección de las víctimas de guerra y, más importante para los propósitos de este escrito, incluye como crímenes de lesa humanidad imprescriptibles el genocidio "definido en la Convención de 1948 para la Prevención y la Sanción del Delito de Genocidio aun si esos actos no constituyen una violación del derecho interno del país donde fueron cometidos". ${ }^{2}$ No obstante que la Convención habla de la "imprescriptibilidad" de estos delitos "cualquiera que sea la fecha en que se hayan cometido", se han producido los

\footnotetext{
${ }^{1}$ Las negritas son nuestras.

${ }^{2}$ Art. I de la Convención, apartado b).
} 
casos de Estados que han adherido a la Convención con la reserva de que rige para los crímenes cometidos a partir de su entrada en vigor para esos Estados ${ }^{3}$.

La Convención fue aprobada en 1968, pero no se ha escrito sobre sus antecedentes, razón por la cual este artículo se va a concentrar en un debate de la más vasta importancia en la historia universal del derecho constitucional y penal, que tuvo lugar en el Parlamento alemán, el 10 de marzo de 1965, en cuyo transcurso se discutió -para los casos de los crímenes cometidos por el régimen nazi, dentro y fuera del territorio alemán- la prolongación de los términos de la prescripción o su eliminación en absoluto para esos delitos, la validez del principio de la irretroactividad de la ley penal, el principio jurídicoconstitucional que establece que no hay pena sin ley (nulla poena sine lege), y otros que hasta entonces habían sido constitutivos del Estado de derecho alemán ${ }^{4}$, sin perder de vista la preeminencia teórica de la percepción política que estuvo siempre presente.

Después de la Segunda Guerra Mundial, las potencias de ocupación habían establecido que la prescripción de los crímenes nacionalsocialistas fuera suspendida del 30 de enero de 1933 hasta el 8 de mayo de 1945 (en la zona de ocupación francesa y británica) y del 30 de mayo de 1933 hasta el 1 de julio de 1945 (en la zona de ocupación americana). Si los crímenes habían prescrito o si podían ser penalmente perseguidos sería examinado no a partir de las fechas en que se cometieron sino de estas últimas fechas.

Después, los términos fueron regulados por el Código de Derecho Penal, el cual había previsto que los crímenes que estaban penados con prisión perpetua prescribirían a los 20 años. Los crímenes para los que estaba previsto una pena de más de 10 años de prisión prescribirían a los 15 años. Esta es la razón por la cual muchos graves crímenes, entre ellos asesinatos y complicidad de asesinato podrían prescribir en 1960.

Tomando en cuenta esta situación, en 1960, el Partido Social Demócrata de Alemania (SPD) propuso extender el comienzo de los términos de prescripción al 16 de septiembre de 1949, ya que el ejercicio del derecho había quedado suspendido en Alemania por la ocupación extranjera. El proyecto fue rechazado por la Comisión de Derecho del Parlamento.

A nivel internacional había voces de protesta en contra de la incertidumbre legal de los presuntos criminales nazis. Israel, los Estados Unidos y la URSS ejercían sus críticas. En 1964, la República Democrática Alemana había aprobado una ley que dispuso la no prescripción de los crímenes de guerra nacionalsocialistas.

El asunto de cuándo debían prescribir los crímenes nacionalsocialistas, de si debían prescribir o de si debía eliminarse totalmente la prescripción para este tipo de delitos continuó en la discusión político-jurídica en la República Federal de Alemania hasta

\footnotetext{
${ }^{3}$ Los subrayados son nuestros.

${ }^{4}$ El debate completo está contenido en el documento Deutscher Bundestag, 170. Sitzung, Bonn, 10. März 1965. https://www.bundestag.de/dokumenten/texarchiv/24031343_debatten04-199958. Este documento lo citaremos en adelante como DB, 170. Sitzung. Las traducciones del alemán son de entera responsabilidad del autor de este escrito.
} 
1979. Empero, el debate "histórico", la "hora estelar" de la discusión jurídica -como se le ha llamado en los medios académicos y en la prensa de Alemania- tuvo lugar en el Parlamento germano en 1965. A reseñar y comentar este debate se concentra el presente escrito.

Los partidos políticos del espectro alemán de entonces, y vigentes hasta hoy con la diferencia de que después se han agregado un par de nuevos partidos, fueron el Partido Social-Demócrata de Alemania (SPD), La Unión Cristiano-Demócrata (CDU), el Partido Liberal-Democrático (FDP) y la Unión Cristiano-Social (CSU). Como se sabe, hasta hoy es tradicional la alianza CDU-CSU y que incluye, coyunturalmente, como en 1965, al FDP. En el debate, los partidos individualmente considerados no tuvieron una sola posición, es decir que los parlamentarios inscritos para participar en él plantearon sus argumentos de acuerdo a su propia conciencia. El debate tuvo lugar en torno a dos propuestas presentadas y al informe del Ministro Federal de Justicia, todos vinculados con la manera de tratar con los crímenes cometidos por el régimen nacional-socialista. Debemos señalar que durante todo el debate existió una condena unánime de los crímenes cometidos por el régimen nazi.

\section{EL DEBATE}

\section{El Vicepresidente, Dr. Dehler, concede la palabra al diputado Benda, primer ponente (CSU/CSU).}

El Dr. Benda centró su posición menos en la reacción pública sobre los asuntos de la orden del día, que en los motivos del asunto de fondo. Pidió una discusión sin apasionamiento y rechazó toda presión del extranjero, invocando al parlamento a actuar bajo la "presión del convencimiento propio".

Su propuesta concreta fue la siguiente:

“De acuerdo a nuestra actual proposición, el Artículo 67 (del Código Penal) debe ser modificado de tal manera que no sea posible en absoluto prescripción alguna para la persecución penal de los crímenes para los que está prevista una condena de por vida". 5

El Dr. Ernst Benda, de ilustre carrera constitucional en la República Federal de Alemania, ya cuestionaba con su propuesta el principio fundamental de Estado de derecho que es la irretroactividad de la ley penal, salvo cuando beneficia al reo, y percibía de inicio que existían motivos respetables en ambas partes de la argumentación en torno a un debate de naturaleza política y jurídica. Recordaremos, a este respecto, que Aristóteles entendía la "política" en su verdadero concepto, como ciencia "arquitectónica", cuyo fin puede "involucrar los fines de las otras ciencias" para "salvar el bien del Estado", (Capítulo 2, del Libro Primero de su Ética Nicomaquea). ${ }^{6}$

"Este Parlamento representa a un pueblo alemán..., un pueblo, en el que el Nacionalsocialismo, la falsa doctrina del Nacional-Socialismo ha sido superada". 7

\footnotetext{
${ }^{5}$ DB, 170. Sitzung, p. 8519.

${ }^{6}$ Aristóteles, 384-322, Obras, ed. Aguilar, 1982, pp. 272-273.

${ }^{7}$ DB, 170. Sitzung, p. 8520.
} 
Esta es una cita del Dr. Benda que se refiere a un elemento constitutivo del Estado: el "pueblo alemán", que ya representa el marco político de referencia no ausente del debate.

El 18 de enero de 1871 se fundó el Imperio Alemán con la proclamación del Rey de Prusia como Kaiser de Alemania y el gran unificador de las centenas de Estados alemanes en torno a Prusia fue Bismarck. El 16 de abril de 1871, se aprueba la Constitución del Imperio Alemán. El Dr. Benda arguye que, desde este año, 1871, existe la posibilidad de interrumpir judicialmente la prescripción y, bajo ciertas circunstancias, hacerlo varias veces para, así, posibilitar una persecución de crímenes por más de 20, 40, 60 e incluso más años.

El diputado ponente señala que es consciente de la problemática jurídico-constitucional de la cuestión en debate y que no quiere banalizarla, pero, para él, ciertamente el núcleo de la problemática reside en otro lugar.

“En el núcleo de la controversia jurídica (...) está la cuestión de la comprensión del Estado de derecho (...) ¿Es el Estado de derecho, así como nosotros lo entendemos hoy? ¿O es otro, uno cambiante, como yo pienso (...), un concepto material del Estado de derecho, que contiene algo diferente? El Estado de derecho hoy tiene también que esforzarse en alcanzar la justicia, no pudiendo naturalmente descuidar el importante bien jurídico de la seguridad jurídica olvidándola o descuidándola. Tiene, como lo dice la Corte Constitucional Federal, que emprender esta no siempre simple consideración en el caso concreto; tiene que decidirse a hacer realidad la justicia.

"Aquí ya estamos fuera de la discusión jurídica. ¿Qué es entonces lo que nosotros hacemos en esta casa, lo que nosotros hacemos en la política? ¿En esta casa en el plano de la comunidad o en el plano que fuera? Al final es igual si nosotros estamos aquí como juristas o como diputados de otras profesiones en nuestra vida privada: nosotros perseguimos, sin embargo, -aun cuan incompleto pueda ser nuestro resultado- acercarnos en algo a la justicia. Este es, al mismo tiempo, el núcleo de la preocupación del Estado de derecho y allí se encuentra la cuestión jurídica con la cuestión política.

"Por ello, pienso yo que la discusión sobre si se trata aquí de una cuestión de derecho o de una cuestión política es ociosa. Es tanto jurídica como política. Los 'artesanos juristas', entre los que me cuento, perseguimos darle (a la justicia) una forma jurídica a través de la fina mecánica del derecho. En el encuentro de la justicia participamos todos. Este es no es solo un trabajo especial de los juristas; este es un trabajo de todos". 8

Estos tres pasajes de la intervención del Dr. Benda son fundamentales en cuanto a la naturaleza del contenido del debate del Parlamento. Un "concepto material del Estado de derecho" supone que ese Estado de derecho no es formal, tiene que alcanzar la justicia y hacerla realidad, y la discusión sobre si esa es una cuestión jurídica o política es ociosa porque es "tanto jurídica como política".

\footnotetext{
${ }^{8}$ Ibid., p. 8522. Las negritas son nuestras.
} 
El Dr. Benda no explica qué es lo que él comprende por justicia. El concepto es tratado tanto en el campo de la filosofía como de la ciencia política, y, en este caso, en la subdisciplina de la filosofía política. En la Grecia clásica se entendía la justicia en términos subjetivos en cuanto parte del principio de que es la virtud la que produce la justicia. Así sucede en Platón, quien afirma que la justicia es la armonía del alma consigo misma y en la igualdad de sus relaciones sociales; Aristóteles, a su vez, señala que la virtud regula la vida en común entre los hombres, y, es especialmente claro cuando dice que la virtud que sirve a la comunidad no es personal, sino política. ${ }^{9}$ Concepto hoy especialmente importante porque no es el hombre como sujeto moral, sino el ciudadano como un ser social dentro de un Estado el punto de partida de todo derecho.

Después de la Grecia clásica y su desarrollo en Roma, se había ingresado a una "Edad Media" de la discusión en torno a la justicia. Después, el concepto de justicia empieza a entenderse en un sentido objetivo que va más allá de la teoría de la virtud, y la concibe como una medida para la determinación de normas de acción morales, jurídicas, sociales y políticas. Se produjeron concepciones como la de Hobbes, John Locke y Jean-Jacques Rousseau. Los escritos de Rousseau, especialmente "El Contrato Social" (1762), influyeron decisivamente en la Revolución Francesa y en todo el debate sobre la democracia y la justicia hasta el siglo XX. Él señala que los hombres no conocen ni el bien ni el mal en su estado de naturaleza, y que libres de toda influencia civilizadora, sus pasiones no están activas. La desigualdad empieza con las instituciones sociales. Se establecen relaciones duraderas de desigualdad y dependencia. Se ajusta el contrato social no para reestablecer la libertad natural ya perdida, sino para volver a edificarla en un estadio más elevado de libertad social. Para Rousseau el pueblo no es una suma de individuos, es decir no es un conjunto cuantitativo de personas, sino uno cualitativo de ciudadanos. Hobbes y Locke tuvieron un concepto numérico de la mayoría, como sucede hasta hoy. En contraposición a ellos, Rousseau propone un cambio de la naturaleza humana, una "desnaturalización" del hombre, una civilización del hombre natural. Una similitud interesante con la teoría política de Maquiavelo, para quien, por lo menos de acuerdo al autor de este escrito, la civilización es una segunda naturaleza impuesta por el Estado sobre la primera caracterizada por la ambición. El hombre para Rousseau tiene que ser, a través de una democracia directa, autor de las leyes a las que él se somete. Rousseau propone un orden político-jurídico ideal para alcanzar la justicia, solo que una democracia directa no es posible hoy como para los griegos o los ginebrinos.

Dentro del concepto objetivo y moderno de la justicia, Rawls anuncia que cada persona tiene un derecho igual a un sistema de libertades fundamentales lo más amplio posible, un sistema que tiene que ser compatible con la libertad de todos. Afirma, además, que en relación a todas las existentes y fácticas desigualdades sociales y económicas, cada persona debe exigir la demostración de que, en una situación determinada, el sistema otorgue la ventaja mayor posible a las personas menos beneficiadas.

En el marco de este concepto objetivo de la justicia puede distinguirse dos elementos: la igualdad y la universalidad jurídica, lo que deja en segundo plano la discusión moral. La justicia no debería limitarse a equilibrar las diferentes expectativas existentes, porque

${ }^{9}$ H. Münkler/M. Llanque, (edit.) Konzeptionen der Gerechtigkeik, 1999, pp. 58 y 63-64. 
entonces ella se colocaría en una situación siempre cambiante con relación a sus diferentes concepciones materiales. Como señala Münkler, profesor de la Universidad Humbolt de Berlín, ante la multiplicidad de las concepciones existentes, entonces, hay dos categorías que deben tenerse en cuenta: la ley y el bien común ${ }^{10}$. Este también es un concepto semántico, pero que, en lugar de buscar coordinar diferentes medidas con relación a la asignación de diferentes bienes y valores, debería estimular conductas políticas y sociales conjuntas privilegiando e incentivando el bienestar común. La acción política con visión tiene un ingrediente de incertidumbre y por ello buscará estabilizar esta incertidumbre a través de las normas jurídicas. La justicia y el bien común, como aspiraciones, y la ley concreta pueden ser comprendidos como canales tanto clásicos como actuales, porque siempre pueden ser fuentes de inspiración para tomar forma en la realidad, aunque tendiendo a ser temporalmente cada vez más vinculante. De esta manera la acción política se hace posible y la ley, orientada al bien jurídico mayor del bienestar común, participa en la creación de la justicia.

Los principios y las normas jurídicas puedes ser concebidas en un sentido universal en cuanto son adoptados por muchos Estados, mientras que el bien común está más relacionado con un pueblo determinado, es decir, con uno de los elementos constitutivos del Estado. Cuando se habla de la justicia y de su relación inmanente con el bienestar común y el derecho, entonces, estamos incluyendo en el fondo del razonamiento al Estado $\mathrm{y}$, cuando lo hacemos así, traemos a la mente el concepto de sus aspiraciones a su grandeza, a su dignidad y a su destino. Las grandes amenazas para los pueblos son afrontadas por los Estados. Son sus instituciones las que con espíritu creativo rompen las formalidades de los principios del derecho cuando tienen que hacerlo para reconstituirlos a fin de crear o reconstruir la justicia. Pero, el Estado tiene que tener a un pueblo real como uno de sus elementos constitutivos para cumplir con su tarea. "Solo existe un Estado alli donde las fuerzas de los individuos están centralizadas y unidas en un todo" "11, nos dice Hegel. Un Estado, entonces, sin un pueblo real y solo con un "pueblo" heterogéneo pierde pronto su centro, cuando las fuerzas centrífugas de éste se imponen sobre él.

Hay una cuestión importante que también toca en el debate el Dr. Benda. Dice que perseguir la justicia es "el núcleo de la preocupación del Estado de derecho y allí se encuentra la cuestión jurídica con la cuestión política." Hubo en Alemania en el transcurso de su historia intelectual una clara oposición entre Hans Kelsen y Carl Schmitt, respecto a la relación entre el derecho y la política. Kelsen eleva la norma del derecho a fundamento del Estado. No importa su origen ni su contenido. La Constitución, norma máxima, el legislador, los tribunales y la ley constituyen un sistema. Schmitt, por su parte, representa la preeminencia de la política sobre el derecho. La política se sirve del derecho como su forma técnica para expresar su voluntad. La existencia del Estado y el orden jurídico-constitucional que establece es dependiente de la política. Este asunto es más claro en el Derecho Internacional Público, pues es la voluntad política de los Estados la que crea derecho, a través de los tratados y la costumbre (Art. 38 del Estatuto de la Corte Internacional de Justicia). El Dr. Benda no adhiere al pensamiento kelseniano ni tampoco

\footnotetext{
${ }^{10}$ Ibid., p. 18.

${ }^{11}$ G.W.F., Hegel, Die Verfasssung Deutschands, 1966, p. 33.
} 
al de Schmitt. Para él, simplemente, el Parlamento alemán tiene que actuar políticamente para reformular el Estado de Derecho, cambiando el principio de la irretroactividad de la ley penal porque la necesidad así lo exige para alcanzar la justicia. La cuestión "es tanto jurídica como política" y la discusión sobre si es una o la otra es "ociosa".

El Dr. Benda también habla del "concepto material del Estado de Derecho". Vamos enseguida a glosar las páginas de un voluminoso libro de Derecho Constitucional, del cual fue uno de los editores y contribuyentes, publicado años después, en el que nos explica lo que entiende a este respecto ${ }^{12}$. Antepone el concepto material del Estado de Derecho al concepto formal del Estado de Derecho. El Estado formal de Derecho supuso el final de un debate iniciado a comienzos del siglo XIX. Pero, "para comprender postulados constitucionales como el del Estado de Derecho son decisivos la evolución histórica y los cambios en la concepción del Estado". La emergente burguesía trataba de liberarse de la tutela autoritaria del Estado accediendo a las garantías jurídicas necesarias. El Dr. Benda señala que R. Thoma, en una lección magistral con motivo de su incorporación a la Universidad de Tubinga, cita a Lasker, para quien "bajo el Estado de Derecho la vulneración del Derecho es el peor de los males, no debiendo ser tolerada ...", como para H. Maurus, quien se pregunta por el contenido del Estado de Derecho ("No es Estado de Derecho aquél en el que exista o pueda existir legalmente la injusticia”). El Estado de Derecho burgués no ofrece una respuesta suficiente a este respecto, dice el Dr. Benda. Por eso, señala, nada impide que respetando solo las formas en las que se crea y aplica el Derecho aparezca la mayor de las injusticias. Paradójicamente, el mismo Estado nacionalsocialista siguió ajustándose a las formalidades tradicionales. Respetando esas formalidades, incluso un Estado democrático puede mantener una injusticia material. La Constitución solo regula la reorganización del Estado, pero es neutral en lo que se refiere a los valores. Un Estado de Derecho formal puede resultar en un "caparazón vacío". En cambio, el Estado material de Derecho se pegunta por el contenido y la orientación de la actividad estatal. El Derecho es más que la forma del Derecho. "La ley Fundamental (de la República Federal de Alemania) se reconoce orientada hacia un Estado de Derecho que debe ser interpretado en sentido material'. El Estado material de Derecho tiene que conciliar con la voluntad de justicia. "En cualquier caso, no es superflua la adjetivación de democrático y social para el Estado de Derecho". El Dr. Benda se refiere aquí al Art. 20 (1) de la Constitución alemana. Hasta aquí las glosas que hemos hecho de las páginas mencionadas de su contribución en el libro cuyo título se encuentra en la cita que antecede.

Volvemos al debate en el Parlamento alemán y seguimos con la brillante participación del Dr. Benda. El Ministro de Justicia, Bucher, había afirmado en el Parlamento de manera categórica que una prolongación de los términos de prescripción violaría el Art. 103 de la Constitución y todos los principios del Estado de Derecho alemán. El Art. 103 tiene tres incisos, de los cuales es el (2) el que se supone es aludido por el Ministro: (2) "Un acto sólo podrá ser penado si su punibilidad estaba establecida por ley anterior a la comisión del acto". El principio más importante, al que seguro también se refiere, es el

\footnotetext{
${ }^{12}$ Benda, Maihoffer, Vogel, Hesse, Heyde: Berlín, 1994; ed. en español Manual de Derecho Constitucional, 1996, pp. 487-491.
} 
de la irretroactividad de la ley penal, cuando no beneficia al reo. El mismo encabezado del Art. 103 dice: [Derecho a ser oído, prohibición de leyes penales con efectos retroactivos y el principio de ne bis in idem].

El Dr. Benda dijo que respeta la posición del Ministro pero que la considera equivocada. Refiriéndose al Ministro, que no era jurista, el Dr. Benda dijo que los no juristas suelen empezar sus mensajes con la frase: "usted como jurista tendría que saberlo naturalmente...". Y continúa: "Este es el resultado en nuestro país a veces todavía algo autoritario. Cuando el Ministro de Justicia afirma que esto es así, entonces la gente dice: entonces así tiene que ser".

El Dr. Benda afirma que el Ministro utiliza tácticamente su posición y, respondiéndole, deja en claro que hay un llamado en favor de lo que él plantea de no menos de 76 Profesores de Derecho Penal y Derecho del Estado. Y, enseguida cita el escrito del Profesor Bachof: "de acuerdo a nuestro convencimiento científico - no convencimiento político- no existe consideración alguna de Derecho Constitucional en contra de una prolongación de los actuales términos de la prescripción para la persecución de hechos de genocidio". ${ }^{13}$ Además, señaló que, en tan solo cuatro días, había recibido igual opinión de 76 Profesores de diferentes universidades, así como de otras personalidades del mundo académico. Otros no lo habían hecho por sus posiciones como jueces, etc. Para el Dr. Benda, entonces, era clara la posición de la ciencia jurídica alemana en favor de la posición que representaba. Más aún, cita también a uno de los más antiguos profesores alemanes de Derecho, al Dr. Gustav Boehmer, quien se había manifestado en contra de un "doctrinarismo apodíctico", de acuerdo al cual la prolongación de los términos de prescripción iría en contra de la Constitución.

"Para los ponentes sobre todas aquellas consideraciones de naturaleza jurídica está simplemente la de que el sentimiento de derecho de un pueblo sería corrompido de una manera insostenible si asesinatos tendrían que quedar sin pena no obstante que ellos podrían ser penados". ${ }^{4}$

Para el Dr. Benda no puede incluirse en la discusión el perdón o el olvido. De esta manera, las víctimas serían en primer lugar legitimadas.

“Quien, apelando a estos antecedentes, propone llegar a un final semejante, seguro parte de la premisa de que castigando a los criminales se le está imponiendo un mal al pueblo alemán, y que sería mejor para nosotros no imponerles pena alguna, aceptando que lo que sucedió es algo que se tiene que hacer".

$$
(\ldots)
$$

"El (un miembro de su misma fracción CDU/CSU) me ha dicho que por el honor de la nación tiene que terminarse con este proceso. Señoras y señores, honor de la naciónesta es para mí una de las últimas razones por la que yo pienso que aquí tenemos que prolongar o suprimir los términos de la prescripción"

\footnotetext{
${ }^{13}$ DB, 170. Sitzung, p. 8522.

${ }^{14}$ Ibid., p. 8524.
} 


\section{$(\ldots)$}

"Insisto en decir que -y ello pertenece para mí al concepto del honor de la nación- este pueblo alemán no es un pueblo de criminales y que a este pueblo tiene que permitírsele que por su propia voluntad busque no ser identificado con estos criminales, sino ser liberado de estos criminales, que puede, mejor dicho y más claro, liberarse por sí mismo de estos criminales". ${ }^{15}$

¿Habla el Dr. Benda en términos jurídicos o hay aquí elementos de carácter político que imprimen su razonamiento para proponer la eliminación de los términos de prescripción con carácter retroactivo?

Él ya había afirmado en el Parlamento que la cuestión en debate era una de naturaleza jurídico-política. Vamos a citar a Carl Schmitt, quien, como ya lo adelantamos, representa la posición de la preeminencia de la política sobre el derecho: "la aportación de un Estado normal consiste sobre todo en producir 'dentro' del Estado y su territorio una pacificación completa, esto es, en procurar, 'paz, seguridad y orden', y crear así la situación normal que constituye el presupuesto necesario para que las normas jurídicas puedan tener vigencia en general, ya que toda norma presupone una situación normal y ninguna norma puede tener vigencia en una situación totalmente anómala por referencia a ella". ${ }^{16}$

Que el Dr. Benda haya buscado un equilibrio en las perspectivas en torno a la naturaleza del debate, ya lo habíamos puesto en claro. Pero Schmitt afirma algo sumamente interesante: que es un presupuesto para la vigencia del derecho en general que un Estado "normal" cree en su territorio una "situación normal", en sentido contrario, que ninguna norma puede tener vigencia en una situación "totalmente anómala". ¿Todos los Estados son normales, en la medida de un Estado creador de lo que llamamos civilización? Obviamente que no. Pero, precisamente en Alemania, donde se han desarrollado muchas de las más grandes concepciones filosófico-políticas de los últimos siglos, se había llegado a una etapa de degeneración de la política y de abuso del poder que condujo a una de las etapas de genocidio más perversas en la historia de la humanidad. Esa, desde luego no era una "situación normal" para la vigencia del derecho, aunque ese régimen, como lo había señalado el mismo Dr. Benda, haya observado las formalidades del derecho.

¿Y cuál es el interés del "pueblo alemán”, del cual habla el Dr. Benda? ¿Qué es el interés de un pueblo, en términos generales? ¿Es algo abstracto o concreto? ¿Es un concepto político o jurídico, o es ambos a la vez? Hemos recordado el antiguo debate entre el pensamiento kelseniano y el de Schmitt, cuyo resultado aparentemente le había dado la razón a Kelsen, aunque la percepción de Schmitt siempre ha estado presente en la historia del país. En Alemania y en su población, lleno de "pleonexia" y de "phronesis", el estudio del poder y la lógica del conflicto ha sido altamente lúcido, pero tendieron a olvidar con soberbia la "sophrosyne", especialmente durante el régimen nazi. Y en 1965, un nuevo y formidable debate tiene lugar en el parlamento alemán y otra vez allí se cruzaron los argumentos jurídicos y políticos. Nuevamente se habló del interés del pueblo alemán,

\footnotetext{
15 Ibid., p. 8526.

${ }^{16}$ C. Schmitt: Berlín, 1933; ed. En español El Concepto de lo Político, 1998, p. 75
} 
"des deutschen Volkes", tan cara denominación para un pueblo a cuya capacidad de razonamiento mucho le debe la humanidad.

La justicia, un concepto filosófico-político, prima sobre los principios de derecho, como el de la irretroactividad de la ley penal, porque las garantías establecidas para la protección de los intereses de una persona no pueden estar sobre el deber del Estado de proteger el interés del pueblo alemán. El derecho que no crea justicia se pierde en un mero formalismo, en un conjunto de normas hechas de papel, sin otra trascendencia que no sea la de servir a la manipulación en el momento de su redacción o a quienes la sostienen en el tiempo para la preservación de sus intereses privados, que no son los del bien común. "El Estado, en cuanto espíritu de un pueblo, es al mismo tiempo la ley que penetra en todas sus relaciones', la costumbre y la conciencia de sus individuos, por eso la constitución de un determinado pueblo depende en general del modo y de la cultura de su autoconciencia". ${ }^{17}$ Cuando el Dr. Benda habla del pueblo alemán está partiendo en su raciocinio del concepto del Estado, y siendo que la Constitución depende de la cultura de su autoconciencia, en los términos de Hegel, propone el camino para extraer a Alemania de la indignidad a la que le había conducido el régimen nazi, para reivindicar a ese pueblo y posibilitarle el encuentro con un destino que lo extraiga de la defensiva moral en la que se encontraba, estigmatizando los crímenes de genocidio y de lesa humanidad y condenando a los culpables, no importa el tiempo transcurrido desde cuando esos crímenes fueran cometidos.

Cuando una Constitución es de papel, es decir meramente formal, surgen las controversias y, paradójicamente, la inseguridad y la incertidumbre jurídica. En tal caso, lo jurídicamente permitido no es sano ni deseable para la salud de una sociedad nacional. La injusticia se nutre de sí misma con la imposición reiterada de unas normas que no crean su contrario. El círculo vicioso no encuentra su final. La justicia sigue siendo una quimera. Debe existir, entonces, un solo resultado de la conciliación entre política, -tal como la definió Aristóteles, según lo hemos visto- y derecho, en función del interés general del Estado, es decir de lo que debe ser un orden constitucional que excluye lo que corrompe su existencia y su "telos" orientado permanentemente a la realización de la justicia.

La propuesta sobre la imprescriptibilidad de los crímenes cometidos durante el régimen nazi buscaba regenerar la conciencia del pueblo alemán, era el enfrentamiento contra los abusos de poder cometidos por ese régimen, la vivencia de una verdadera metástasis del genocidio que bloqueaba el desarrollo de su historia, era su catarsis. Si volvemos a Hegel, cuando dice que "la Constitución política es és en primer lugar' la organización del Estado y el proceso de su vida orgánica...", ${ }^{18}$ entonces el proceso de la vida orgánica de la Constitución alemana había degenerado y necesitaba ser sometido a una revisión terapéutica.

\footnotetext{
${ }^{17}$ G.W.F., Hegel: Berlín, 1821; ed. en español Fundamentos de la Filosofía del Derecho, 1993, p. 720.

Las negritas son nuestras.

${ }^{18}$ Ibid., 711.
} 


\section{Continúa el debate. La palabra es concedida por el Vicepresidente Dr. Schmid al diputado Hirsch, el segundo ponente (SPD).}

El diputado Hirsch expresa que está totalmente de acuerdo con el Dr. Benda. Empero, se pregunta:

"¿Sería correcto o no prolongar los términos de prescripción para el genocidio en general, si se procurase abstraerse completamente del problema del genocidio nazi?" (...)

"No se trata ciertamente de una 'desnazificación"”. (...), “de lo que se trata es tan solo de la cuestión de si los términos de prescripción para asesinato deben ser prolongados. $\mathrm{Ni}$ siquiera se trata de una prolongación de los términos de prescripción para delincuentes en general. La dicción general a este respecto es la siguiente: la prescripción para criminales nazis. Ella no es falsa. Todos los crímenes nazis, fuera de los homicidios, han prescrito, y nadie piensa en prolongar los términos de prescripción otra vez. Solo se trata de la cuestión: prolongación de los términos de prescripción para asesinato". 19

Importantes precisiones del Dr. Hirsch, en cuanto a que la propuesta de los dos ponentes, la del Dr. Benda y la de él mismo, se concretan a los criminales acusados de asesinato. En el proyecto de la Comisión para la Reforma del Derecho Penal del propio Parlamento está previsto, según lo manifiesta el Dr. Hirsch, que los términos de prescripción para asesinato deben ser prolongados a 30 años. También recuerda que, según el Gobierno Federal, este problema de la prescripción es en parte de carácter material y en parte de derecho formal, es decir de naturaleza político-jurídica y también jurídico formal de respeto a los principios de un Estado de derecho. El Gobierno Federal quería evitar que los hechos penales ya prescritos puedan ser retomados nuevamente y que aquellos que no habían prescrito pudieran aun ser perseguidos con la prolongación de los términos de prescripción a 30 años.

También llamaba la atención al hecho de que, en la Comisión de derecho penal, la cual señala- ha trabajado varios años documentos desde la época de la República de Weimar y del Imperio Alemán, nunca ha sido controvertida la cuestión de la prolongación del término de prescripción a por lo menos 30 años, aun cuando no se trataba de genocidio, sino de asesinato, muy diferente a la posición del Ministro de Justicia expresada en el debate.

Hay parlamentarios que opinan, señala el Dr. Hirsch, que hay presión de la "opinión pública mundial" y que "no debería cederse" a ella. Ello podría suceder si tuviera una posición falsa en el asunto.

"Pero ya que ella es correcta en el asunto [...] no hay fundamento razonable alguno, porque hay una presión, para decidir de otra manera, como sí se hubiera decidido, si no se habría dado presión alguna".

${ }^{19}$ DB. 170. Sitzung, p. 8527 
"El Consejo de la Federación ha eliminado la pena de muerte para los asesinos. De igual manera, la consecuencia es, entonces, que para asesinos que merecían la pena de muerte no debe haber tampoco término de prescripción alguno".

[...] "Nosotros hemos presentado otra propuesta todavía, la cual supone un cambio en la Constitución. [...] Nosotros somos de la opinión de que corresponde a la dignidad de esta casa y a la importancia de este problema, emprender de una manera indubitable e indudable el cambio en la Constitución en el sentido de que no hay prescripción alguna para asesinato cuando tampoco hay ya más la pena de muerte para asesinato". ${ }^{20}$

El Dr. Hirsch se plantea también la posibilidad de que, dentro del marco de la problemática jurídica, la prolongación de los términos de prescripción que se apruebe por una simple ley no pueda ser rechazada después por la Corte Constitucional. "Sería una catástrofe si así sucediera", dijo. Recuerda que el Dr. Benda tenía dudas sobre si el asunto debería ser decidido a través de una simple ley o de un cambio en la Constitución, porque en ambos casos se atentaría supuestamente contra los principios del Estado de Derecho de la República Federal.

"Se trataba ciertamente de la discusión en torno al llamado principio del Estado de Derecho para aquellos que se habían ocupado en concreto con el Art. 103 de la Constitución y de la cuestión de si los términos de la prescripción pertenecen a las prescripciones que no pueden ser cambiadas retroactivamente. No necesariamente esta es una cuestión del principio del Estado de derecho, sino un problema del Art. 103, pero puede ser cambiado". 21

Es impresionante la formulación del Dr. Hirsch cuando hace alusión a cómo un Art. de la Constitución puede corromperla en cuanto no crea justicia tratando de amparar con la prescripción a criminales. Unos veían en la segunda parte del Art. $103,{ }^{22}$ un principio de Estado de Derecho, el Dr. Hirsch, como el Dr. Benda, veían allí un simple formalismo, un congelamiento sin telos, ni capacidad para responder a la necesidad de justicia, luego de la profanación por el régimen nazi de todos los valores elementales de la convivencia y de todas las normas no escritas. Dice, después, que hay una mayoría no solo cuantitativa sino también cualitativa de profesores de derecho penal y de ciencia política que están de acuerdo en que puede cambiarse la cuestión de la irretroactividad para los casos de genocidio con una ley del Parlamento. Considera muy poco probable que la Corte Constitucional la declare inconstitucional.

“[...] Estoy de acuerdo con usted, señor Benda, en que reside en interés del pueblo alemán, y también de la gran mayoría de quienes han sido alguna vez partidarios del

\footnotetext{
${ }^{20}$ Ibid., 8529. Las negritas son nuestras.

${ }^{21}$ Ibid., 8530. Las negritas son nuestras.

${ }^{22}$ Art. 103 de la Constitución "[Derecho a ser oído, prohibición de leyes penales con efectos retroactivos y el principio de ne bis in idem], (2) Un acto solo podrá ser penado si su punibilidad estaba establecida por ley anterior a la comisión del acto.
} 
Nacional-Socialismo, si nosotros nos libramos de los criminales, de los asesinos, y hacemos todo lo posible para no tener que vivir con asesinos". ${ }^{23}$

EI Vicepresidente del Parlamento, Dr. Schmid, da por concluida la sustentación de las dos ponencias presentadas y abre el debate general, ofreciéndole la palabra al Dr. Barzel (CDU/CSU).

Después de las palabras introductorias del caso, el Dr. Barzel dice lo siguiente: "En esta discusión, que es una_discusión política, cada uno siente que el presente sin pasado no existe...". ${ }^{24}$ Como se desprenderá del conjunto de su intervención, tiene una posición crítica con respecto a la propuesta sustentada por los doctores Benda y Hirsch. Al calificar la discusión de "política", la entiende en el sentido común del término, es decir, de una que tiene lugar siguiendo los intereses parlamentarios del momento para lograr simpatías o algo semejante. No entiende la política en el sentido aristotélico, ni tampoco presupone que exista un concepto de filosofía político-jurídica como la justicia.

"Este hombre (Hitler) es el gran responsable frente al pueblo alemán y también frente a aquellos, de cuyo sentimiento patrio y de cuyo idealismo abusó. Este pueblo alemán no es colectivamente culpable. [...] Nosotros siempre hemos expresado nuestro reconocimiento a este pueblo, a toda su historia, como también al honor de sus soldados alemanes. Y lo seguiremos haciendo. Nosotros siempre hemos separado limpiamente delitos criminales de errores políticos. Y siempre lo vamos a hacer. Solo quien ha cometido delitos debe ir al tribunal."

"Sucede diferente en el caso de un error politico [...]. No hay instancia alguna que pueda confirmar la existencia y la medida de la culpa en el caso de un error político". 25

Tal vez la formulación no haya sido la más correcta, pues correspondía al debate políticojurídico tratar en concreto de la prolongación o eliminación de los términos de prescripción para los criminales nazis. Todo el pueblo alemán no estaba acusado ni pendían sobre todos sus miembros penas que corrieran el riesgo de prescribir. Se había hablado de la justicia en nombre del pueblo alemán, bien jurídico mayor y también concepto filosófico-político, dentro de cuyo marco era altamente lúcido poner en cuestionamiento el Estado de Derecho formal. ¿Qué es, por lo demás, un error político? Esta es una cuestión interesante pero que no atañe al propósito del presente artículo.

Lo que si era evidente para el Dr. Barzel era que el Nazismo había destruido la democracia de Weimar, el Estado de Derecho y los derechos humanos.

Su posición está clara cuando cita el informe del Gobierno Federal:

\footnotetext{
${ }^{23}$ DB, 170. Sitzung, p. 8530.

${ }^{24}$ Loc. Cit. Las negritas son nuestras.

${ }^{25}$ Loc. cit.
} 
“El Gobierno Federal apoyará al Parlamento alemán en sus esfuerzos para crear una posibilidad que satisfaga la justicia dentro del marco de los principios fundamentales del Estado de Derecho". ${ }^{26}$

Luego dice que las posibilidades de la justicia terrenal son limitadas y que "justicia" y "judicium" no es lo mismo. ${ }^{27}$ Nadie había pensado en paralizar los tribunales ni tampoco esperado que así sucediera poniendo en cuestión un principio formal del Estado de Derecho, el cual tenía que ser repensado a la luz de un bien jurídico mayor y de los mandatos de la política que exigían una respuesta a una situación anormal en el desarrollo de la vida de un Estado. Y aun si hubiera pensado el orador que el Poder Judicial se habría visto sobrepasado con la aprobación de la ponencia en discusión, los hechos han demostrado lo contrario.

\section{El Vicepresidente, Dr. Schmid, cede la palabra al Dr. Bucher, Ministro Federal de Justicia.}

El Ministro empezó señalando que no hablaba en nombre del Gobierno Federal sino de sí mismo. Trae a colación el hecho de que el Parlamento noruego se había mostrado también en contra de la permanencia de la prescripción para casos semejantes a los tratados allí y que los parlamentarios noruegos se habían imaginado "lo terrible que sería si Bormann apareciera públicamente..." Por esta razón, prefería el Ministro no hablar de personas ni tampoco de prominentes juristas y políticos, sino de la responsabilidad de construir "nuestra propia opinión".

"Las razones de mi rechazo de una prolongación (se supone de los términos de la prescripción) a través de una ley con efecto retroactivo residen básicamente en cuestiones fundamentales de derecho [...]. Ambos fundamentos, la seguridad jurídica, de una parte, y la justicia material, de la otra, tienen rango constitucional.

[...] "La Corte Constitucional Federal ha repetido esto claramente y le ha reconocido al legislador la libertad de decidirse en el caso concreto entre ambos postulados y, dentro del marco de ciertas fronteras, de preferir la justicia material o la seguridad jurídica. Preferir la justicia material, es decir, es decir la necesidad de una expiación, solo puede tener sentido si nosotros pudiéramos ser del convencimiento de que la prolongación de los términos de prescripción actualmente vigentes ayudaría realmente a un triunfo convincente. Justamente este convencimiento yo no lo tengo". ${ }^{28}$

Un tanto tratando de aludir al carácter alemán, recuerda que Lenin no tenía mucho respeto por las capacidades revolucionarias de los alemanes, pues había dicho que cuando se les encargaba asaltar un tren, lo primero que hacían era comprar los pasajes en la boletería. También recuerda que Theodor Heuss rechazaba hablar de una "culpa colectiva" y prefería hacerlo de una "vergüenza colectiva", así como a Golo Mann, quien hablaba de que una mitad de la nación se encontraba en los tribunales. De allí, concluye que la carga procesal con una ley que prolongue los términos de prescripción se vería tremendamente

\footnotetext{
${ }^{26}$ Ibid., p. 8531.

${ }^{27}$ De la justicia ya hemos escrito. Judicium es la paralización de los tribunales.

${ }^{28}$ Ibid., p. 8533
} 
sobrecargada. Este argumento parecía banal en cuanto pretendía dejar todo, dentro del marco de las leyes existentes, a la inercia y a la formalidad.

"En función de estas consideraciones, no creo que una prolongación de los existentes términos de prescripción con carácter retroactivo sea un indubitable mandamiento de la justicia". ${ }^{29}$

¿El fracaso de la justicia ante la presunta carga procesal y ante la inercia y la formalidad?

"El Art. 103, punto 2, de la Constitución le ha dado un rango constitucional al viejo principio fundamental de derecho "nulla poena sine lege" 30 . Sobre la interpretación de este principio se han dado ante todo tres consideraciones.

La primera [...] extrae del Art. 103, punto 2, una prohibición especialmente rigurosa. De acuerdo a ella, tiene que ser especialmente prohibida toda ampliación de las competencias que sucedan al hecho, toda ampliación del poder del Estado y toda pretensión penal estatal [...].

De acuerdo a esta concepción, que toma en serio el principio de Derecho de la Constitución, sería inadmisible una prolongación de los términos actuales de la prescripción a través de una simple ley.

Esta concepción tiene todavía una consecuencia más amplia [...]. Si se divisa en el Art. 103, punto 2, un caso especial del principio de Estado de Derecho anclado en el Art. 20, entonces es dudable si esta determinación puede ser quebrada a través de un cambio en la Constitución teniendo en cuenta la garantía para el Principio de Estado de Derecho establecida en el Art. 79 de la Constitución. ${ }^{31}$

En oposición manifiesta a esta opinión esta la concepción de que el Art. 103, punto 2, exige solo que antes del hecho tendría que existir una situación punible determinada con una amenaza de pena determinada, en resumen, solo el 'si' o el 'cómo' de la penalidad tendría que estar fijada jurídicamente antes del hecho.

Esta interpretación deja libre una prolongación de los términos de prescripción a través de una simple ley.

[...] De acuerdo a una tercera concepción, finalmente se extiende la prohibición jurídico-constitucional de la irretroactividad a un conjunto de prescripciones jurídico-materiales de derecho penal. De acuerdo a esta teoría, una prolongación de los actuales términos de prescripción a través de una simple ley sería violatoria de la Constitución, si la prescripción se considerase como derecho penal material". ${ }^{32}$

\footnotetext{
${ }^{29}$ Ibid., p. 8535

${ }^{30}$ No es delito el acto no sancionado por las leyes.

${ }^{31}$ Art. 20: (3) "El Poder legislativo está sometido al orden constitucional; los poderes ejecutivo y judicial, a la ley y al Derecho". El Art. 79: (1) "La ley Fundamental sólo puede ser reformada por una ley que expresamente modifique o complemente su texto. (2) Una ley de este carácter requiere la aprobación de una mayoría de dos tercios de los miembros del Bundestag y de dos tercios de los votos del Bendesrat".

${ }^{32}$ DB, 170. Sitzung, p. 8535
} 
Estas eran las posiciones en pugna en el debate, de acuerdo al Ministro de Justicia. Y se observa, claramente que limitaba su clasificación a posiciones jurídicas sin tomar realmente en cuenta las consideraciones de carácter jurídico-políticas que colocaban en cuestión el formalismo de una Constitución utilizada para amparar una política de genocidio que había colocado al pueblo alemán en una situación de insostenibilidad moral a nivel interno como internacional. Si el 'sí' o el 'cómo' de la penalidad está jurídicamente fijada antes o después del hecho, sigue siendo una cuestión de carácter jurídico, que no llega a responder los argumentos ni el "telos" de la propuesta en favor de la prolongación o eliminación de los términos de prescripción para los delitos cometidos durante el régimen nazi.

Como quienes están en favor de extender o eliminar los términos de prescripción han hablado, especialmente el Dr. Benda, de una justicia material, también el Ministro de Justicia habla de un derecho penal "material". Señala, por otra parte, que el Código de Derecho Penal determina que, ante una diferencia en la ley, desde antes del hecho hasta el momento de la sentencia, tiene que aplicarse la ley más beneficiosa al reo. Los alcances del principio "nulla poena sine lege" residen profundamente en la conciencia jurídica general, pues ella procede -señala el Ministro- de una gran tradición en el desarrollo del derecho y tiene su concreción en casi todos los Estados alemanes de la Federación, así como en la Convención de Derechos Humanos.

"Ante el tribunal y ante el fiscal y ante la policía está ante todo no un criminal, sino un ciudadano, contra quien se investiga y, luego, eventualmente es acusado. Es, de la misma manera, un antiguo principio de derecho, un fundamento de la Constitución, que cada ciudadano pueda sentirse inocente, en tanto no sea sentenciado de acuerdo al derecho". 33

Cuando el Dr. Schäfer interrumpió al Ministro diciéndole que hablaba de otra cosa, le contestó: "hablo de que aquí no se trata de una Carta Magna de asesinos, sino de una Carta Magna de ciudadanos". El diputado Metzger interrumpió, enseguida: "pero usted impide también que se pueda determinar si él es un asesino!". El Ministro respondió: "de eso se trata. El ciudadano es colocado frente al tribunal y alli se confirma si lo es". Una nueva interrupción del diputado Metzger: "no, usted lo impide con la prescripción". "Ese es el sentido de la prescripción. Entonces, tienen que eliminar totalmente el instituto de la prescripción, si son de este punto de vista", respondió el Ministro.

¿Ciudadanos o delincuentes? Es, ciertamente, un principio de derecho que a una persona debe presumírsele inocente mientras no sea condenado. El principio funciona en todo Estado normal, y aquí parece estar la "differentia specífica". Durante el régimen nazi no todos eran ciudadanos, con los derechos a los que se refiere el Ministro, ni alemanes "arios" ni no "arios", sino que todos eran o miembros del régimen -entre quienes se encontraban los que podríamos llamar ejecutores, en torno a quienes gira el debate-, o simpatizantes o víctimas o enemigos de un sistema que pudo convertir el control ciudadano en una maquinaria de aniquilación sistemática por razones ideológico-raciales -si al nazismo podría asignársele una ideología-. La prueba contundente han sido los

${ }^{33}$ Ibíd. pág. 8536. 
millones de muertos que produjo, en el país y fuera de sus fronteras, y las olas de emigración de miles de intelectuales en todas las esferas del formidable mundo académico alemán, especialmente a los Estados Unidos, en donde se crearon universidades especialmente para que ellos pudieran ejercer las cátedras de sus especialidades o continuar con sus investigaciones científicas. ¿Se podía haber medido la perversidad de los crímenes cometidos, y aceptar que están tipificados como tales en la legislación y que rige para esos casos el derecho jurídico-formal, en general, y los términos de prescripción existentes, en especial, dentro del marco de un Estado de Derecho, sin recurrir a la política, en los términos en los que la entiende Aristóteles? Para resolver este problema traeremos a colación otro párrafo del estagirita: "[...] aunque el bien del individuo se identifique con el bien del Estado, parece mucho más importante y más conforme a los fines verdaderos llevar entre manos y salvar el bien del Estado". ${ }^{4}$

"Todavía una palabra fundamental para terminar. "El Profesor Jaspers dice en una entrevista: 'El Derecho está fundado en todo el mundo en una voluntad política'. Quisiera decirlo al revés: El derecho antecede a la política".

Un retorno al viejo debate entre Kelsen e Schmitt, al cual ya hemos hecho referencia. Solo diremos que la política antecede a la existencia misma del Estado. El Dr. Benda encontraba un equilibrio entre el derecho y la política. Él era, a final de cuentas, un ilustre jurista, y, algún tiempo después del debate, fue elegido Presidente de la Corte Constitucional de Alemania, cargo que ejerció durante varios años. No obstante, y como es común en Alemania, siempre tuvo una aguda percepción política. Partiendo de la premisa de que el derecho rige en una situación de normalidad, concluiremos nosotros que la política se activa en su relación con el derecho y con cualquier otra esfera de la vida de un Estado, cuando éste no se encuentra en esa situación de normalidad, para conjurar el riesgo de que él no se convierta en un instrumento para otros fines que no sean los de la justicia orientada al bien común, o que manipule o ignore la realidad que se supone debe regular, es decir que no se convierta en un derecho de papel, como lo decía Hegel.

Schmitt, refiriéndose a las perturbaciones de un Estado estable, dice lo siguiente:

"El derecho, ya sea público o privado, posee su propio ámbito relativamente autónomo como tal, más seguro cuando se encuentre a la sombra de una gran decisión política, por ejemplo, en el marco de un Estado estable. Pero al igual que sucede con todas las esferas de la vida y el pensar humanos, puede ser utilizado en apoyo o en contra de alguna otra esfera. [...] Pues en tal caso el 'imperio del derecho' no significa otra cosa que la legitimización de un determinado status quo en cuyo mantenimiento está lógicamente interesados todos aquellos cuyo poder político o ventaja económica, poseen su estabilidad en el seno de ese derecho". ${ }^{35}$

\footnotetext{
${ }^{34}$ Aristóteles, Op. Cit., p. 273.

${ }^{35}$ Schmitt, Op. Cit., pp. 94-95. Las negritas son nuestras.
} 


\section{EI Vicepresidente, Dr. Schmid, cede la palabra al diputado Jahn (SPD)}

Lo primero que expresa el diputado Jahn es su profunda decepción por lo que el Ministro ha dicho durante media hora del debate, en el fondo porque está en contra de la prolongación de los términos de prescripción, sin que queden claros ni sus motivos ni sus explicaciones.

"La cuestión decisiva es, sin embargo: ¿debe ser respondida simplemente con solo consideraciones jurídicas la monstruosa cantidad de asesinatos, en esta forma sin precedentes en la historia, en esta gran medida, con esta crueldad, o estamos en la obligación, aquí en primer lugar, de encontrar una decisión político-moral?" 36

El diputado Jahn señaló que no se avanzará nada con esta consideración político-moral ni con la afirmación de que el Estado de Derecho precede a las decisiones políticas. Dijo también temer que ignorarían el rol de los juristas en esta discusión si su tarea no es contribuir a encontrar una solución y no hacer lo contrario.

"En esta cuestión el Parlamento tiene que asumir y cumplir su rol político de conducción en singular medida -como siempre-. Es tarea de esta casa [...] mostrar el camino en una cuestión de tan alto nivel político y moral, así como también hacer eficaz la fuerza de convicción en el propio pueblo, la cual es necesaria para hacer realidad y promover la opinión general sobre la necesidad de las decisiones que aquí se exigen."

\section{$[\ldots[$}

"También es peligroso hablar aquí del derecho a la equivocación política. Naturalmente, el derecho al error político tiene que mantenerse [...] también como una parte constitutiva de nuestra libertad. Pero aquí no tenemos nada que ver con el derecho al error político. Con quienes tenemos que ocuparnos han sido asesinos, ellos han sido asesinos en la elemental forma de lo criminal [...], para quienes el derecho al error político no tiene valor; pues hay cosas sobre las que uno no puede equivocarse. Quien asesina -si lo hace directamente o si lo ha hecho desde un escritorio [...] él no puede haberse equivocado, él no puede haber estado en la oscuridad sobre lo que ha hecho". ${ }^{37}$

Interesantes las apreciaciones del diputado Jahn, quien recuerda que en el Parlamento se había debatido ya este asunto de la prescripción hace cinco años. Entonces -afirma el diputado- la "mayoría de esta casa" había tomado otra decisión diferente a la que ahora él y otros diputados representan. Pero, deja entender el diputado Jahn que ese debate no fue pasajero, porque -afirma- durante cinco años vienen discutiendo esta cuestión tanto en el Parlamento como en las Comisiones que había constituido. Hace luego alusiones a la resistencia del Gobierno Federal para realizar las indagaciones que debía haber hecho y, luego, expresa que fue necesario el viaje de fiscales de Hessen a Polonia -utilizando sus vacaciones- para obtener confirmaciones sobre lo sucedido en Auschwitz. También señala que, en un informe del Ministro de Justicia, del 26 de febrero de 1965, se

\footnotetext{
${ }^{36}$ DB. 170. Sitzung, p. 8537.

${ }^{37}$ Ibíd., p. 8538
} 
encuentran frases como "Rudolf Hess, Representante del Führer" o "Karl Dönitz, último Presidente del Reich". ${ }^{38}$

Errores o descuidos o como quiera llamarse a estos hechos, ellos expresan el ambiente de tensión y confusión en la Alemania de entonces.

El diputado Jahn también señala que se ha despertado una gran impresión con el número de sentenciados, pero, al mismo tiempo, se pregunta cuánto de grande ha sido el número de víctimas de aquellos, de cuya responsabilidad se trataba allí.

\section{Aquí ponemos fin a nuestras reseñas y comentarios del debate en el Parlamento alemán, limitadas a las 5 primeras intervenciones.}

En todo el debate Intervinieron el entonces Ministro Federal de Justicia y un total de 14 diputados. No obstante, por razones de espacio, el presente escrito solo contiene las reseñas y comentarios de las intervenciones del primer y segundo ponente, Dr. Benda y diputado Hirsch, respectivamente, del Dr. Barzel y del Dr. Bücher, entonces Ministro Federal de Justicia, y del diputado Jahn.

\section{Después del debate}

Al final se llegó a un compromiso en el Parlamento alemán con una ley del 23 de mayo de 1965: el comienzo de los términos de prescripción para asesinatos con pena de cadena perpetua fue fijada para el 1 de enero de 1950. Es decir que, como los años de prescripción para estos casos era de 20, entonces los criminales nazis con probable pena de cadena perpetua hubieran podido quedar exentos de penalidad alguna en 1970. El Ministro de Justicia, Dr. Bucher, presentó su carta de renuncia al cargo.

Mientras tanto, como ya lo hemos señalado, la Asamblea General de las Naciones Unidas aprobaron la Convención sobre la IMPRESCRIPTIBILIDAD de los Crímenes de Guerra y de los Crímenes de Lesa Humanidad, en 1968. Desde que en Alemania el debate continuaba su propio curso, no adhirió a la Convención, aunque los efectos del que tuvo lugar en 1965 hayan tenido su más grande realización en la decisión de la Asamblea General de las NN.UU., seguramente no sin la muy profesional, eficiente y alta calidad y poder de la diplomacia alemana en los foros internacionales. El núcleo de la Convención, es decir, la introducción en el derecho internacional de la imprescriptibilidad para esos crímenes no fue entendida por varios Estados, que adhirieron a ella con la reserva de que la Convención entraba en vigor para ellos a partir de la fecha de su adhesión, en virtud del principio de derecho de la irretroactividad de la ley penal, salvo cuando favorece al reo, establecida en sus Constituciones, principio que había sido precisamente cuestionado con éxito finalmente por quienes han sido y son creadores de derecho como los académicos y los parlamentarios alemanes.

En abril de 1969, un año antes de que hubieran quedado prescritas las penas para muchos criminales nazis, la Corte Constitucional Federal, estableció la conformidad de la ley

${ }^{38}$ Ibíd., p. 8540 
aprobada en el Parlamento en 1965 con la Constitución. Entretanto, la justicia alemana había estado procesando a más de 10,000 acusados.

Entonces, varios diputados alemanes nuevamente pusieron en el debate del Parlamento Federal el asunto de la prescripción para genocidio, el 26 de junio de 1969. Para los casos de asesinato se elevaron los términos de prescripción a 30 años, 10 años más que los 20 decididos en el 23 de mayo de 1965. Para los criminales nazis con probable pena de cadena perpetua, entonces, los delitos no podían prescribir sino hasta 1980. Cuando se aprobó esta norma, se tuvo en cuenta que entre esos criminales no se incluía a los culpables de genocidio, lo que daba a entender que tal delito aún quedaba para una decisión posterior, dentro del marco de la incansable e incesante batalla jurídico-política en el Parlamento alemán.

El año 1979, se volvió a discutir sobre la prescripción de los crímenes de nacionalsocialistas. La situación política en Alemania había cambiado, pues en el Gobierno se encontraba en el poder la coalición de la Social-Democracia (SPD) con el Partido Liberal (FDP). Además, el Parlamento Europeo se había pronunciado también contra la prescripción del asesinato. Después de cerca de once horas de otro debate de alto nivel en el Parlamento alemán, 255 diputados votaron por la eliminación de la prescripción para el asesinato y 222 en contra. Desde entonces, asesinos de la época nazi recién descubiertos podían ser perseguidos sin consideración de si para ellos habían transcurrido o no los términos de prescripción.

Fue en el fondo un debate de 20 años, uno de los más brillantes en la historia del derecho constitucional y penal que se haya podido producir, con un día de brillo singular, el 10 de marzo de 1965, del cual hemos dado cuenta en este escrito. 